\title{
CARD-FISH analysis of prokaryotic community composition and abundance along small-scale vegetation gradients in a dry arctic tundra ecosystem
}

\section{$\operatorname{AUTHOR}(\mathrm{S}):$}

Ushio, Masayuki; Makoto, Kobayashi; Klaminder, Jonatan; Nakano, Shin-ichi

\section{CITATION:}

Ushio, Masayuki ...[et al]. CARD-FISH analysis of prokaryotic community composition and abundance along small-scale vegetation gradients in a dry arctic tundra ecosystem. Soil Biology and Biochemistry 2013, 64: 147-154

\section{ISSUE DATE:}

2013-09

\section{URL:}

http://hdl.handle.net/2433/175264

\section{RIGHT:}

(C) 2013 Elsevier Ltd.; This is not the published version. Please cite only the published version.; この論文は出版社版でありません。引用の際に は出版社版をご確認ご利用ください。 
Soil Biology \& Biochemistry 64: 147-154

Title: CARD-FISH analysis of prokaryotic community composition and abundance along small-scale vegetation gradients in a dry arctic tundra ecosystem

Authors: Masayuki Ushio ${ }^{1 *}$, Kobayashi Makoto ${ }^{2,3}$, Jonatan Klaminder ${ }^{2}$, Shin-ichi Nakano ${ }^{1}$

Affiliations: ${ }^{1}$ Center for Ecological Research, Kyoto University, 2-509-3 Hirano, Otsu, Shiga 520-2113, Japan, ${ }^{2}$ Climate Impact Research Centre, Umeå University, 981-07, Abisko, Sweden, ${ }^{3}$ Soil Ecology Research Group, Graduate School of Environment and Information Sciences, Yokohama National University, 79-7 Tokiwadai, Yokohama, Kanagawa 240-8501, Japan

*Correspondence to: ushima@ecology.kyoto-u.ac.jp

Tel: +81-77-549-8215, Fax: +81-77-549-8201

Keywords: Archaea; Bacteria; CARD-FISH; Soil microbial community; Tundra ecosystem; Vegetation gradients 


\section{Abstract:}

The size and composition of soil microbial communities have important influences on terrestrial ecosystem processes such as soil decomposition. However, compared with studies of aboveground plant communities, there are relatively few studies on belowground microbial communities and their interactions with aboveground vegetations in the arctic region. In this study, we conducted the first investigation of the abundance and composition of prokaryotic communities along small-scale vegetation gradients $(c a .1-3 \mathrm{~m})$ in a dry arctic tundra ecosystem in Northern Sweden using fluorescent in situ hybridization (FISH) coupled with catalyzed reporter deposition (CARD). The number of prokaryotic cells increased with increasing vegetation cover along vegetation gradients, mainly as a function of increased amounts of soil carbon and moisture. Eubacteria and Archaea constituted approximately $59.7 \%$ and $33.4 \%$ of DAPI-positive cells, respectively. Among the analyzed bacterial phyla and sub-phyla, Acidobacteria and $\alpha$-proteobacteria were the most dominant groups, constituting approximately $13.5 \%$ and $10.7 \%$ of DAPI-positive cells, respectively. Interestingly, the soil prokaryotic community composition was relatively unaffected by the dramatic changes in the aboveground vegetation community. Multivariate analyses suggested that the prokaryotic community composition depended on soil $\mathrm{pH}$ rather than on aboveground vegetation. Surface plants are weak predictors of the composition of the soil microbial community in the studied soil system and the size of the community is constrained by carbon and water availability. In addition, our study demonstrated that CARD-FISH, which is still a rarely-used technique in soil ecology, is effective for quantifying soil microbes. 


\section{Introduction}

Soil microbial communities play a central role in terrestrial ecosystem processes. For example, activities of extracellular enzymes secreted by soil microbial communities fundamentally drive decomposition of organic matter (Sinsabaugh et al., 2009). Growing evidence supports the idea that understanding the size and composition of microbial communities, as well as environmental variables (e.g., temperature), are keys to understanding and predicting the process of decomposition in soils (Balser and Firestone, 2005; Strickland et al., 2009; Schmidt et al., 2011; Bell et al., 2013). Therefore, although the presence of a strong linkage between phylogeny and function remains controversial (Kuffner et al., 2012; Prosser, 2012), elucidating the factors that determine the abundance and composition of soil microbial communities is a promising approach when investigating and understanding the mechanisms governing terrestrial ecosystem processes.

Recent studies have highlighted the effects of aboveground plant communities on the composition and abundance of soil microbial communities, as feedbacks between plants and soil microorganisms can drive terrestrial ecosystem dynamics (Wardle et al., 2004b) such as nutrient cycling (Vitousek, 2006) and aboveground plant community dynamics (Mangan et al., 2010; Miki et al., 2010). One of the most effective approaches for understanding the effects of aboveground plant communities on belowground soil microbial communities is the investigation of soil microbial communities along naturally-occurring vegetation gradients. Examples of such vegetation gradients are found in the Hawaiian archipelago, Swedish boreal forests and regions of glacial retreat in New Zealand (Wardle et al., 1997; Vitousek, 2006; Allison et al., 2007).

Within the arctic region, sharp vegetation gradients are present over small spatial scales within patterned ground systems, but little is known as to the extent to which this sharp zonation is also reflected in the soil microbial community. One example of these sharp 
vegetation gradients can be found within patterned ground systems referred to as non-sorted circles (NSCs), where soil frost processes (cryoturbation) generate sparsely vegetated circle-like features of approximately $1-3 \mathrm{~m}$ surrounded by densely vegetated shrub communities (Fig. 1a, b; see also the site description in Materials and Methods). NSCs cover a large proportion of arctic and sub-arctic landscapes, and are the most common form of patterned ground in arctic regions (Washburn, 1980; French, 2007; Walker et al., 2008). Consequently, the sharp vegetation gradient generated within NSCs, consisting of lichen-dominated plant communities in the center to shrub-dominated communities in the outer domain (Makoto and Klaminder, 2012), are representative of a large part of the dry arctic landscape. Also, this system allows ready replication because many individual NSCs exist under the same climatic conditions in the region (Fig. 1b), which is often not the case in other situations with well-studied vegetation gradients (Wardle et al., 1997; Vitousek, 2006; Allison et al., 2007). Therefore, the NCS system provides a good opportunity to study the extent to which microbial communities co-vary with the aboveground plant community over a considerable proportion of arctic tundra ecosystems.

Prior to the 1990s, there were great difficulties involved in identifying and quantifying microbes in environmental samples. However, subsequent methodological developments in microbial ecology (Sogin et al., 2006; Amann and Fuchs, 2008 and references therein) make it possible to investigate "wild" microbial communities in detail. Fluorescent in situ hybridization (FISH) coupled with catalyzed reporter deposition (CARD) is a microscope-based method that allows quantitative investigation of microbial communities. Because the CARD-FISH method includes a process of tyramide signal amplification, the signal intensity is much stronger than that of the conventional (mono-labeled) FISH method (e.g., Amann et al., 1990). Because of its advantage over conventional FISH analysis, the CARD-FISH method has been widely used for aquatic samples (e.g., Pernthaler et al., 2002; 
Okazaki et al., 2013), and sometimes for marine sediments (Ishii et al., 2004), but applications of CARD-FISH to soil microbial studies are still limited (Eickhorst and Tippkötter, 2008). CARD-FISH is potentially more quantitative than other commonly used methods in microbial ecology, such as DGGE (Muyzer et al., 1993), clone libraries (Giovannoni et al., 1990) and 16S rRNA gene pyrosequencing (Lauber et al., 2009), because microbial cells are directly counted in a microscope field. In addition, CARD-FISH can target a specific microbial genus or species if an appropriate molecular probe is used. Therefore, in terms of phylogenetic resolution, CARD-FISH is superior to using microbial biomarkers such as lipids and quinone (Bååth and Anderson, 2003; Ushio et al., 2010; Takasu et al., 2013), which is another common technique in ecological studies.

In the present study, we used the CARD-FISH method to investigate the abundance and composition of prokaryotic communities along the small-scale vegetation gradients generated within NSCs in a dry arctic tundra system. Previous studies found that the abundance of a soil microbial community was positively correlated with carbon content (an energy resource for heterotrophic microbes) in soil (Fierer et al., 2009), which supports the consensus that carbon availability is a primary limiting factor of soil microbial communities (Vance and Chapin III, 2001). In addition, soil $\mathrm{pH}$ is generally a good predictor of microbial composition and/or diversity (Bååth and Anderson, 2003; Fierer and Jackson, 2006; Lauber et al., 2009). In general, as vegetation communities develop, the soil carbon content increases and soil $\mathrm{pH}$ decreases because of an increased accumulation of soil organic matter (e.g., Wardle et al., 1997). Therefore, we hypothesized that 1) the abundance of the soil prokaryotic community would increase with the observed increase in plant biomass from the center of NSCs towards the outer domains, and that 2) soil $\mathrm{pH}$, in addition to plant communities, would be an important factor influencing the composition of the soil prokaryotic community. 


\section{Materials and Methods}

\subsection{Study site descriptions}

Field research was conducted on the north-facing slope of Mt. Suorooaivi (1193 m a.s.l., $68^{\circ} 16^{\prime} \mathrm{N}, 19^{\circ} 06^{\prime} \mathrm{E}$; Fig. 1a-c), located approximately $20 \mathrm{~km}$ south of Abisko, Northern Sweden $\left(68^{\circ} 18^{\prime} \mathrm{N}, 19^{\circ} 10^{\prime} \mathrm{E}\right)$. The research site is situated at an elevation of $700-750 \mathrm{~m}$. Between 1981 and 2010, the mean annual temperature and precipitation in Abisko were $-0.1^{\circ} \mathrm{C}$ and $335 \mathrm{~mm}$, respectively. The bedrock in the study area is dominated by hard schists.

In the study area, NSCs occur frequently. Within these features, a vegetation change from lichen-dominated plant communities to dense shrub communities occurs over distances of less than 3 meters (Fig. 1d). According to the general theory of NSCs, this vegetation gradient is maintained by intense soil frost processes in the center that gradually decrease towards the sides of the circle (Washburn, 1980; Walker et al., 2008). The species diversity of the vascular plants and the density of the bryophyte community increases with increasing distance from the center of the NSCs (Makoto and Klaminder 2012). More detailed information about the plant community in this system is available in Makoto and Klaminder (2012). From 1984 to 1987 in NSCs near Abisko, the number of frost-free days at a soil depth of $25 \mathrm{~cm}$ ranged between 150 and 190, and the minimum soil temperature in the center of a NSC was $-16^{\circ} \mathrm{C}$ (Josefsson, 1990). Macro-climate conditions are considered to be identical within the NSC system because of the small spatial scale, which allows us to focus on micro-scale effects of the aboveground vegetation gradient on the belowground microbial community.

\subsection{Soil sample collection and physicochemical properties}

In each NSC, samples from six locations were collected in late September in 2011, along a 
transect from a point at which silty soil from deeper soil layers was exposed at the soil surface (i.e. the center of the NSC) towards a point in the outer domain where vascular plants dominated. These locations were designated $0,1,2,3,4$ and 5, where increasing numbers indicate an increasing distance from the center (Fig. 1d). At each location, one mineral soil sample $(\sim 10 \mathrm{~cm}$ depth) was collected with a stainless soil corer $(7.3 \mathrm{~cm}$ in diameter $)$. In addition to the mineral soil samples from the six locations, humus layer samples, which occur at locations 3, 4, and 5, were collected and combined as one humus sample because the physicochemical properties of humus samples at location 3, 4, and 5 are similar (Makoto et al. unpublished). The soils from six replicate NSCs were sampled. In total, we collected 42 soil samples (six replicate NSCs $\times$ [six locations + one humus sample]). The soil samples were immediately taken back to the laboratory, sieved to remove stones and plant roots, and homogenized thoroughly for the subsequent analyses. For the collected soil samples, soil

water contents were determined by drying the soil samples to constant weight. Soil $\mathrm{pH}$ (soil:water $=1: 10$ ), carbon, and nitrogen contents as well as aboveground vegetation were previously determined. Briefly, ranges of physicochemical properties of mineral soils in our study site are as follows: soil $\mathrm{pH} 4.5-6.2$, organic carbon content $0.3-24.1 \%$, total soil nitrogen $0.02-1.12 \%$ and soil water content $9.5-54.3 \%$.

\subsection{Cell counts and CARD-FISH}

Total prokaryotic cell abundance was determined by counting under microscopic fields after staining their double-stranded DNA with 4', 6-deamidino-2-phynylindole (DAPI) (Porter and Feig, 1980). To investigate prokaryotic community composition along the NSC vegetation gradients, the CARD-FISH method was applied to each sample. We generally followed the experimental protocol described in Eickhorst and Tippkötter (2008) with several modifications. Approximately $0.5 \mathrm{~cm}^{3}$ of fresh bulk soil from each soil sample was weighed 
and transferred to 2-ml plastic micro-tubes. The samples were fixed with $4 \%(\mathrm{w} / \mathrm{v})$ freshly prepared particle-free paraformaldehyde solution, and the suspension was stored at $4^{\circ} \mathrm{C}$ overnight $(\sim 16 \mathrm{~h})$. The fixed samples were washed twice with $1 \times \mathrm{PBS}$, centrifuged at $10,000 \mathrm{~g}$ for $5 \mathrm{~min}$ after each washing, and stored in PBS/ethanol $(1: 1)$ at $-20^{\circ} \mathrm{C}$ for further processing. Then, $100 \mu \mathrm{l}$ of the fixed sample was diluted with $900 \mu \mathrm{l}$ of PBS/ethanol and dispersed by ultrasonic dispersion at minimum power for $20 \mathrm{~s}(10 \%$; UR-21P, TOMY, Tokyo).

A volume of $20 \mu \mathrm{l}$ of the dispersed sample was diluted in $10 \mathrm{ml}$ of sterilized water, and the suspension was filtered on a polycarbonate filter $(0.2 \mu \mathrm{m}$ pores, $\varphi 25 \mathrm{~mm}$, Millipore, Billerica) placed on a nitrocellulose filter $(0.45 \mu \mathrm{m}$ pores, $\varphi 25 \mathrm{~mm}$, Millipore, Billerica), which were mounted in a glass holder for the filtration. After the filtration, the filters were dipped in $0.2 \%$ low melting point agarose (Sigma) and dried in an incubator at $46^{\circ} \mathrm{C}$. The agarose-embedded filters were then incubated with a lysozyme solution (10 mg lysozyme, $100 \mu 10.5$ M EDTA [pH 8.0], $100 \mu 11 \mathrm{M}$ Tris- $\mathrm{HCl}$ [pH 8.0], $800 \mu 1$ of sterilized water), which were placed in a sealed petri dish at $37^{\circ} \mathrm{C}$ for $1 \mathrm{~h}$. After washing with MQ water, the filters were incubated with methanol containing $0.15 \% \mathrm{H}_{2} \mathrm{O}_{2}$ for $30 \mathrm{~min}$ at room temperature to inactivate endogenous peroxidase activity. The filters were washed with MQ water and dehydrated by dipping them in $98 \%$ ethanol and subsequently air drying. After this step, filters were stored at $-20^{\circ} \mathrm{C}$ until further processing.

For the CARD-FISH analysis, nine probes, which target potentially dominant soil microbial groups (e.g., Lauber et al., 2009), were applied to quantify the abundance of various microbial groups in the soil samples (Table 1). For the in situ hybridization, the filter was cut into small pieces and incubated with $300 \mu$ of hybridization buffer $(900 \mathrm{mM} \mathrm{NaCl}$, $20 \mathrm{mM}$ Tris- $\mathrm{HCl}[\mathrm{pH} 8.0], 10 \%[\mathrm{w} / \mathrm{v}]$ dextran sulfate, $2 \%[\mathrm{w} / \mathrm{v}]$ blocking reagent [Roche, Mannheim, Germany], $0.1 \%$ [w/v] sodium dodecyl sulfate, and formamide (its concentration 
depending on the probe)) and $2 \mu 1$ of Horseradish peroxidase-labeled probe solution (50 ng $\mu 1^{-1}$; Greiner Bio-One, Germany). The stock solution of the blocking reagent $(10 \% \mathrm{w} / \mathrm{v})$ was prepared in maleic acid buffer (100 mM maleic acid, $150 \mathrm{mM} \mathrm{NaCl}, \mathrm{pH} 7.5)$. The optimal formaldehyde concentration and hybridization temperature were determined by testing a series of formamide concentrations $(0-60 \%)$ and two hybridization temperatures (35 and $46^{\circ} \mathrm{C}$ ) to produce maximum detection rates (Table 1 and Fig. S1). The hybridization reaction was conducted in a 24-well microplate overnight (up to $18 \mathrm{~h}$ ) with mild agitation (10 rpm). The microplate was sealed carefully with parafilm to prevent evaporation of the hybridization buffer. After hybridization, the filter pieces were washed with $0.05 \%(\mathrm{v} / \mathrm{v})$ Trition $\mathrm{X}-100$ amended with PBS for 15 min. Stringent washing was omitted, as Wendeberg (2010) reported that it did not make a significant difference to CARD-FISH results because CARD-FISH works with lower concentrations of the probe than does FISH using fluorochrome-labeled probes. After removing excess liquid from the filters, they were incubated in $30 \mu 1$ of amplification mixture $(1 \times$ amplification diluent [PerkinElmer, MA, USA]:40\% $[\mathrm{w} / \mathrm{v}]$ dextran sulfate:fluorescein-tyramide reagent [PerkinElmer, MA, USA] $=$ 25:25:1) in a 24 -well microplate and incubated in the dark for $45 \mathrm{~min}$ at $37^{\circ} \mathrm{C}$. The filters were subsequently dipped in $0.05 \%(\mathrm{v} / \mathrm{v})$ Triton X-100 amended with PBS for 5-10 min in the dark, washed in MQ water, and dehydrated with $98 \%$ ethanol. The filters were then mounted on a glass slide with an anti-fading reagent (Citifluor [Citifluor, Leicester, UK]: Vectashield [Vector Laboratories, Burlingame, CA, USA] = 4:1) containing approximately 1 $\mu \mathrm{g} \mathrm{ml} \mathrm{l}^{-1}$ of DAPI.

For each sample, two or three microscope pictures of DAPI-positive cells and the corresponding FISH-positive cells with UV (330-350 nm excitation by U-MWU, Olympus) and blue (460-490 nm excitation by U-MWB2, Olympus) excitation, respectively, were taken at 400-magnification using an epifluorescence microscope (BX60, Olympus, Japan) and an 
attached digital-camera (EOS Kiss X5, Canon, Tokyo, Japan; Fig. S2 shows examples of CARD-FISH images). The microscope pictures were then processed with an automated image processing program, the "EBImage" package of the software R (Sklyar et al., 2012).

\subsection{Statistics}

For all statistical analyses, the free statistical environment package $\mathrm{R}$ was used ( $\mathrm{R}$ Development Core Team, 2012). The additive mixed model was applied to analyze the relationship between distance from the center and prokaryotic cell abundance, including individual NSCs as a random factor. The additive mixed model was conducted using the "mgcv" package (Wood, 2004). The relationships between soil physicochemical properties and prokaryotic cell abundance were analyzed using a linear mixed model followed by model selection based on Akaike information criteria (AIC). Total plant biomass, the number of plant species, soil organic carbon, total soil nitrogen, soil $\mathrm{pH}$, and moisture content were initially included as explanatory variables in the linear mixed model. These variables were chosen because they dramatically change along the vegetation gradient (Makoto and Klaminder, 2012), and because they could have direct/indirect influences on the soil microbial community. For example, total plant biomass and the number of plant species can influence plant productivity (Tilman et al., 1997) which affects carbon inputs to soil via root exudates and litter production. Soil organic carbon, total nitrogen and water content could be a rough index for soil resource availability because they are essential for microbial activity (e.g., Vance and Chapin III, 2001). The linear mixed model and model selection were conducted using the "nlme" package (Pinheiro et al., 2009). Principal component analysis (PCA) was performed to analyze overall patterns of prokaryotic community composition along the NSC vegetation gradients. In addition, redundancy analysis (RDA) was performed to analyze the relationships between the prokaryotic community composition, soil 
physicochemical properties and aboveground plant vegetation. Detailed vegetation data such as the number of moss species and lichen species are available for these sites (Makoto and Klaminder, 2012), but these data did not improve the predictive power of the RDA presented in this study. Therefore, only total plant biomass and numbers of species were used to reduce the number of explanatory variables. Significance of the variables used in the RDA was tested by a permutation test (9999 permutations). The multivariate analyses were conducted using the "vegan" package (Oksanen et al., 2008). 


\section{Results}

\subsection{Prokaryotic cell abundance}

The numbers of DAPI-positive cells in the mineral soil increased with increasing vegetation cover occurring outwards from the center of the NSC (Fig. 2a). The humus layer had higher numbers of DAPI-positive cells than the mineral soil. Additive mixed model analysis excluding the humus layer samples showed that distance from the center had a significant effect on prokaryotic cell abundance $(P<0.01$; Fig. $2 b)$. The number of DAPI-positive cells increased from location 0 to 3 , and then slightly decreased towards location 5 (i.e., it showed a humpbacked shape: Fig. 2b).

To briefly explore the factors that influence prokaryotic cell abundance in the studied system, linear mixed model analyses followed by model selection based on AIC were performed. Soil water content and organic carbon content were selected as significant factors influencing the prokaryotic cell abundance (Fig. 2c, d). Soil water and organic carbon content were positively correlated with the number of DAPI-positive cells $(P<0.0001)$.

3.2 Composition of the prokaryotic community along the vegetation gradients and factors influencing the community composition

According to the CARD-FISH analysis, Eubacteria and Archaea constituted $59.7 \%$ and $33.4 \%$, respectively, of the prokaryotic cells in the NSC systems. The sum of the relative abundances of Eubacteria and Archaea (i.e., cells detected with the EUB338 and ARCH915 probes) was equivalent to $93 \% \pm 3.0$ (standard error of the mean; SEM) of DAPI-positive cells (Fig. S3). Among the analyzed bacterial phyla and sub-phyla, $\alpha$-proteobacteria and Acidobacteria were the most dominant phyla, constituting approximately $13.5 \%$ and $10.7 \%$ of DAPI-positive cells, respectively (Fig. 3). The other phyla and sub-phyla, i.e., $\beta$-proteobacteria, $\gamma$-proteobacteria, $C F B$ and Actinobacteria, were present in relatively minor 
numbers.

To explore the effects of aboveground vegetation on the overall prokaryotic community composition, we performed multivariate analyses. PCA revealed the general pattern of the composition of the prokaryotic community in the NSC system (Fig. 4). The first two principal components (PCs), PC1 and PC2, explained $41.2 \%$ and $14.4 \%$ of total variation in the community composition, respectively. A linear mixed model analysis suggested that changing aboveground vegetation with increasing distance from the center did not significantly influence the PCs $(P>0.05$; Fig. 4a and Fig. S4).

In addition to the PCA, we conducted RDA to investigate variables that explained the prokaryotic community composition in the NSC system. Aboveground plant biomass data, plant species number, and soil physicochemical properties (Makoto and Klaminder, 2012) were included as explanatory variables, and the permutation test was conducted to find significant factors influencing the community composition (9999 permutations). The analysis showed that only soil $\mathrm{pH}$ was a marginally significant factor affecting the prokaryotic community composition $(F=2.153, P=0.055)$. The relative abundances of Acidobacteria and $\alpha$-proteobacteria tended to decrease with increasing soil $\mathrm{pH}$, but the correlations were not significant $(P>0.05)$. 


\section{Discussion}

The major components of the prokaryotic community, revealed by CARD-FISH analysis, were not influenced by sharp zonation in the aboveground vegetation (Fig. 3 and 4), while prokaryotic abundance showed a humpbacked distribution along the vegetation gradient (Fig. 2). At our study site, the mean value of the relative abundance of Archaea exceeded $30 \%$, which is much higher than previously reported when using the pyrosequencing technique (Bates et al., 2011). In the following subsections, possible determinants of the abundance and composition of the soil prokaryotic communities as well as some methodological issues are discussed.

\subsection{Prokaryotic cell abundance}

In line with our first hypothesis, the number of DAPI-positive cells increased from location 0 to 3, and then slightly decreased towards location 5 (i.e., it showed a humpbacked shape: Fig. 2b). The observed pattern of changes in the abundance of microbes with ecosystem development is qualitatively similar to the results found previously by Wardle et al. (2004a) who reviewed studies conducted in forest ecosystems. In addition, further analysis showed that soil water and organic carbon content were positively correlated with the number of DAPI-positive cells (Fig. 2; $P<0.0001$ ). That microbial processes are carbon and moisture limited is also supported by a recent laboratory-based study using soil samples from the same vegetation gradients in which heterotrophic respiration rates increased as moist organic matter was mixed into the mineral soil (Klaminder et al., 2013). The results of this study are also in agreement with previous studies, which found that microbial biomass was significantly correlated with soil water and carbon availability in various ecosystems (Allison et al., 2007; Fierer et al., 2009; Welc et al., 2012). 


\subsection{Composition of the prokaryotic community along the vegetation gradients}

The detection rate of prokaryotic cells by CARD-FISH analysis $(93 \% \pm 3.0$; Fig. S3) is considerably higher than the rate reported in a previous study which used the conventional (mono-labeled) FISH (Kobabe et al., 2004). This suggests that the CARD-FISH method is a more effective method for investigating soil microbial communities than the conventional FISH method. Compared with other studies that applied CARD-FISH, the relative abundance of Archaea (ca. 33.4\%) in the arctic tundra soils is similar in range to that previously reported for farmland and paddy soils (e.g., $28.1 \%$ for a sandy loam paddy soil; Eickhorst and Tippkötter, 2008), but higher than the value reported for marine sediments (Ishii et al., 2004). Some studies that used the pyrosequencing technique reported much lower values (e.g., 1.7\%; Bates et al. 2011). Caution should be taken in comparing different studies because of probable methodological differences between them. We suggest that whether Archaea is dominant or rare in soil environments should be further tested by simultaneously applying different methodologies such as CARD-FISH, multi-color FISH (Wendeberg, 2010), quantitative PCR (Fierer et al., 2005) and 16S rRNA gene pyrosequencing. In terms of bacterial phyla and sub-phyla, $\alpha$-proteobacteria and Acidobacteria were the most dominant (Fig. 3). Other pyrosequencing studies have also reported their dominance in soil samples (Lauber et al., 2009; Chu et al., 2010).

The multivariate analysis showed that the prokaryotic community composition was relatively unaffected by vegetation change along the vegetation gradients (Fig. 4). Previous studies have found that the phylogenetic composition of microbial communities (e.g., fungi-to-bacteria ratio) changes as the vegetation changes along soil chronosequences (Allison et al., 2007; Welc et al., 2012). Our study does not support these results: one possible explanation for this is that our study did not include fungi that have often been 
analyzed in previous studies using the lipid biomarker technique (Allison et al., 2007; Welc et al., 2012). Significant changes in microbial community composition would probably be observed if fungi were included in the CARD-FISH analysis, but our current dataset does not allow us to quantify the fungal abundance. It might also be that there was simply no difference in microbial community composition along the vegetation gradients, or the coarse-scale taxonomic resolution (i.e., domain, phyla or sub-phyla level) in our study obscured changes in microbial community composition. Additional analysis such as $16 \mathrm{~S}$ rRNA gene pyrosequencing would help to address these possibilities. Furthermore, prokaryotic cells are very tiny and may easily be dispersed over small spatial scales, such as those in this study, along with percolating soil-water or water moving as a result of cryogenic suction ( $\sim 3 \mathrm{~m}$; Fig. 1a). Because of this possible dispersal process, significant changes in prokaryotic community composition might not be observed along the vegetation gradients. That the bulk soil itself is subjected to significant soil motion in the studied gradient (Makoto and Klaminder, 2012) suggests that cyclic soil movement within the studied soil unit may also have contributed to the homogenous mixture of the microbial community. Microbial dispersal via possible vectors such as wind or soil water may also contribute to the homogeneous microbial community composition.

\subsection{Factors influencing the prokaryotic community composition}

RDA analysis showed that soil $\mathrm{pH}$ was only a marginally significant factor affecting prokaryotic community composition. Many studies have shown soil microbial community diversity and/or composition to be strongly regulated by soil pH (Bååth and Anderson, 2003; Fierer and Jackson, 2006; Lauber et al., 2009; Rousk et al., 2010; Welc et al., 2012). The marginally significant effect of $\mathrm{pH}$ on the microbial community observed here might indicate that other environmental conditions, such as low soil temperatures, constrain the composition 
of the microbial community. That microbial processes are strongly constrained by environmental conditions at the study site is supported by ${ }^{14} \mathrm{C}$ dating, suggesting that millennia-old carbon pools are present in the upper mineral soil (Becher et al., 2013). Another possible explanation for the marginal effect of $\mathrm{pH}$ seen in our study is, again, the relatively small-spatial scale of our study system and the possible within-site dispersal of microbial cells, because previous studies were conducted at much larger spatial scales (i.e., from $180 \mathrm{~m}$ to a continental scale) than within a single NSC. As already indicated by Martiny and colleagues (2011), determinant factors of microbial community composition may depend on the spatial scale of a target study system. Contributions of microbial migration processes to community establishment, which are not well understood, might be more important at our site than at the previously studied sites at larger spatial scales. That is, dispersal limitations may contribute to the significant differences in microbial community composition found in previous studies. Comparison of microbial community composition and environmental controls at different spatial scales might provide an opportunity to understand the relative importance of microbial dispersal processes and environmental controls on community composition.

Importantly, methodological differences between our study and previous studies might also contribute to some extent to the observed differences in the results. Our study used cell abundance-based data, but previous studies used biomass-based data (Bååth and Anderson, 2003; Rousk et al., 2010; Ushio et al., 2010) or 16S rRNA gene-based data (Fierer et al., 2005; Lauber et al., 2009; Chu et al., 2010). Microbial biomarker, quantitative PCR and pyrosequencing techniques destroy microbial cells and extract biomarker compounds (e.g., signature lipids) or 16S rRNA genes from microbes. Conversely, the CARD-FISH method allows the direct counting of microbial cells under a microscopic field. Further studies that examine the influences of these methodological differences would benefit researchers in 
microbial ecology.

\subsection{Conclusions}

The CARD-FISH method was an effective technique for investigating soil microbial communities (see also Eickhorst and Tippkötter, 2008). The technique provided fundamental data on the abundance and composition of soil prokaryotic communities in arctic tundra soils and suggested that: 1) the abundance of prokaryotic communities significantly increased along with increasing vegetation cover, 2) Archaea, $\alpha$-proteobacteria, and Acidobacteria were dominant in the soils, and 3) the prokaryotic community composition was relatively stable, even along dramatic vegetation gradients in the NSCs. These results generally follow those of previous studies, but some results (e.g., the dominance of Archaea) are inconsistent with earlier studies which have used 16S rRNA gene pyrosequencing. Further analyses using multiple methodologies would provide important insights into the belowground components of dry arctic tundra ecosystems. 


\section{Acknowledgements}

We thank Mr. Yusuke Okazaki for assistance with the CARD-FISH methodology, Mr. Hiroyuki Takasu for his help with the experiments, and members of the Nakano laboratory in the Center for Ecological Research at Kyoto University for their comments on this study. We also thank two anonymous referees for providing constructive suggestions. Partial support for this study was provided by Grants-in-Aid for Scientific Research (23370010) from Japan Society for the Promotion of Science (JSPS). M.U. and K.M. are financially supported by Research Fellowships of JSPS (23-586 and 24-3240, respectively). 


\section{References}

Allison, V.J., Condron, L.M., Peltzer, D.A., Richardson, S.J., Turner, B.L., 2007. Changes in enzyme activities and soil microbial community composition along carbon and nutrient gradients at the Franz Josef chronosequence, New Zealand. Soil Biology and Biochemistry 39, 1770-1781.

Amann, R., Fuchs, B.M., 2008. Single-cell identification in microbial communities by improved fluorescence in situ hybridization techniques. Nature Reviews Microbiology 6, 339-348.

Amann, R.I., Krumholz, L., Stahl, D.A., 1990. Fluorescent-oligonucleotide probing of whole cells for determinative, phylogenetic, and environmental studies in microbiology. Journal of Bacteriology 172, 762-770.

Bååth, E., Anderson, T.H., 2003. Comparison of soil fungal/bacterial ratios in a pH gradient using physiological and PLFA-based techniques. Soil Biology and Biochemistry 35, 955-963.

Balser, T.C., Firestone, M.K., 2005. Linking microbial community composition and soil processes in a California annual grassland and mixed-conifer forest. Biogeochemistry $73,395-415$.

Bates, S.T., Berg-Lyons, D., Caporaso, J.G., Walters, W.A., Knight, R., Fierer, N., 2011. Examining the global distribution of dominant archaeal populations in soil. ISME Journal 5, 908-917.

Becher, M., Olid, C., Klaminder, J., 2013. Buried soil organic inclusions in non-sorted circles fields in northern Sweden: Age and Paleoclimatic context. Journal of Geophysical Research: Biogeosciences. doi:10.1002/jgrg.20016

Bell, T.H., Yergeau, E., Maynard, C., Juck, D., Whyte, L.G., Greer, C.W., 2013. Predictable bacterial composition and hydrocarbon degradation in Arctic soils following diesel 
and nutrient disturbance. ISME Journal. doi:10.1038/ismej.2013.1031

Chu, H., Fierer, N., Lauber, C.L., Caporaso, J.G., Knight, R., Grogan, P., 2010. Soil bacterial diversity in the Arctic is not fundamentally different from that found in other biomes. Environmental Microbiology 12, 2998-3006.

Eickhorst, T., Tippkötter, R., 2008. Improved detection of soil microorganisms using fluorescence in situ hybridization (FISH) and catalyzed reporter deposition (CARD-FISH). Soil Biology and Biochemistry 40, 1883-1891.

Fierer, N., Jackson, R.B., 2006. The diversity and biogeography of soil bacterial communities. Proceedings of the National Academy of Sciences of the United States of America $103,626-631$.

Fierer, N., Jackson, J.A., Vilgalys, R., Jackson, R.B., 2005. Assessment of soil microbial community structure by use of taxon-specific quantitative PCR assays. Applied and Environmental Microbiology 71, 4117-4120.

Fierer, N., Strickland, M.S., Liptzin, D., Bradford, M.A., Cleveland, C.C., 2009. Global patterns in belowground communities. Ecology Letters 12, 1238-1249.

French, H.M., 2007. The Periglacial Environment. John Wiley and Sons LtD., Chichester, UK, pp. 458

Giovannoni, S.J., Britschgi, T.B., Moyer, C.L., Field, K.G., 1990. Genetic diversity in Sargasso Sea bacterioplankton. Nature 345, 60-63.

Ishii, K., MuVümann, M., MacGregor, B.J., Amann, R., 2004. An improved fluorescence in situ hybridization protocol for the identification of bacteria and archaea in marine sediments. FEMS Microbiology Ecology 50, 203-212.

Josefsson, M., 1990. The geoecology of subalpine heaths in the Abisko Valley, northern Sweden; a study of periglacial conditions. In: Dep. Physical Geography. Uppsala University, Uppsala, pp. 187. 
Klaminder, J., Giesler, R., Makoto, K., 2013. Physical mixing between humus and mineral matter found in cryoturbated soils increases short-term heterotrophic respiration rates. Soil Biology and Biochemistry 57, 922-924.

Kobabe, S., Wagner, D., Pfeiffer, E.M., 2004. Characterisation of microbial community composition of a Siberian tundra soil by fluorescence in situ hybridisation. FEMS Microbiology Ecology 50, 13-23.

Kuffner, M., Hai, B., Rattei, T., Melodelima, C., Schloter, M., Zechmeister-Boltenstern, S., Jandl, R., Schindlbacher, A., Sessitsch, A., 2012. Effects of season and experimental warming on the bacterial community in a temperate mountain forest soil assessed by 16S rRNA gene pyrosequencing. FEMS Microbiology Ecology 82, 551-562.

Lauber, C.L., Hamady, M., Knight, R., Fierer, N., 2009. Pyrosequencing-based assessment of soil $\mathrm{pH}$ as a predictor of soil bacterial community structure at the continental scale. Applied and Environmental Microbiology 75, 5111-5120.

Makoto, K., Klaminder, J., 2012. The influence of non-sorted circles on species diversity of vascular plants, bryophytes and lichens in Sub-Arctic Tundra. Polar Biology 35, $1659-1667$.

Mangan, S.A., Schnitzer, S.A., Herre, E.A., MacK, K.M.L., Valencia, M.C., Sanchez, E.I., Bever, J.D., 2010. Negative plant-soil feedback predicts tree-species relative abundance in a tropical forest. Nature 466, 752-755.

Martiny, J.B.H., Eisen, J.A., Penn, K., Allison, S.D., Horner-Devine, M.C., 2011. Drivers of bacterial ß-diversity depend on spatial scale. Proceedings of the National Academy of Sciences. $108,7850-7854$

Miki, T., Ushio, M., Fukui, S., Kondoh, M., 2010. Functional diversity of microbial decomposers facilitates plant coexistence in a model of plant-microbe-soil feedback. Proceedings of the National Academy of Sciences of the United States of America 
$107,14251-14256$.

Muyzer, G., De Waal, E.C., Uitterlinden, A.G., 1993. Profiling of complex microbial populations by denaturing gradient gel electrophoresis analysis of polymerase chain reaction-amplified genes coding for $16 \mathrm{~S}$ rRNA. Applied and Environmental Microbiology 59, 695-700.

Okazaki, Y., Hodoki, Y., Nakano, S.I., 2013. Seasonal dominance of CL500-11 bacterioplankton (phylum Chloroflexi) in the oxygenated hypolimnion of Lake Biwa, Japan. FEMS Microbiology Ecology 83, 82-92.

Oksanen, J., Kindt, R., Legendre, P., O'Hara, B., Simpson, G.L., Solymos, P., Stevens, M.H.H., Wagner, H., 2008. vegan: Community Ecology Package.

Pernthaler, A., Pernthaler, J., Amann, R., 2002. Fluorescence in situ hybridization and catalyzed reporter deposition for the identification of marine bacteria. Applied and Environmental Microbiology 68, 3094-3101.

Pinheiro, J., Bates, D., DebRoy, S., Sarkar, D., R_Development_Core_Team, 2009. nlme: Linear and Nonlinear Mixed Effects of Models. In.

Porter, K.G., Feig, Y.S., 1980. The use of DAPI for identifying and counting aquatic microflora. Limnology and Oceanography 25, 943-948.

Prosser, J.I., 2012. Ecosystem processes and interactions in a morass of diversity. FEMS Microbiology Ecology 81, 507-519.

R Development Core Team, 2012. R: A language and environment for statistical computing. R Foundation for Statistical Computing, Vienna, Austria.

Rousk, J., Brookes, P.C., Bååth, E., 2010. The microbial PLFA composition as affected by pH in an arable soil. Soil Biology and Biochemistry 42, 516-520.

Schmidt, M.W.I., Torn, M.S., Abiven, S., Dittmar, T., Guggenberger, G., Janssens, I.A., Kleber, M., Kogel-Knabner, I., Lehmann, J., Manning, D.A.C., Nannipieri, P., Rasse, 
D.P., Weiner, S., Trumbore, S.E., 2011. Persistence of soil organic matter as an ecosystem property. Nature 478, 49-56.

Sinsabaugh, R.L., Hill, B.H., Follstad Shah, J.J., 2009. Ecoenzymatic stoichiometry of microbial organic nutrient acquisition in soil and sediment. Nature 462, 795-798.

Sklyar, O., Pau, G., Smith, M., Huber, W., 2012. EBImage: Image processing toolbox for R.

Sogin, M.L., Morrison, H.G., Huber, J.A., Welch, D.M., Huse, S.M., Neal, P.R., Arrieta, J.M., Herndl, G.J., 2006. Microbial diversity in the deep sea and the underexplored "rare biosphere". Proceedings of the National Academy of Sciences 103, 12115-12120.

Strickland, M.S., Lauber, C., Fierer, N., Bradford, M.A., 2009. Testing the functional significance of microbial community composition. Ecology 90, 441-451.

Takasu, H., Kunihiro, T., Nakano, S.-I., 2013. Estimation of carbon biomass and community structure of planktonic bacteria in Lake Biwa using respiratory quinone analysis. Limnology. doi:10.1007/s10201-013-0402-3

Tilman, D., Knops, J., Wedin, D., Reich, P., Ritchie, M., Siemann, E., 1997. The influence of functional diversity and composition on ecosystem processes. Science 277, $1300-1302$.

Ushio, M., Kitayama, K., Balser, T.C., 2010. Tree species-mediated spatial patchiness of the composition of microbial community and physicochemical properties in the topsoils of a tropical montane forest. Soil Biology \& Biochemistry 42, 1588-1595.

Vance, E.D., Chapin III, F.S., 2001. Substrate limitations to microbial activity in taiga forest floors. Soil Biology and Biochemistry 33, 173-188.

Vitousek, P., 2006. Ecosystem science and human-environment interactions in the Hawaiian archipelago. Journal of Ecology 94, 510-521.

Walker, D.A., Epstein, H.E., Romanovsky, V.E., Ping, C.L., Michaelson, G.J., Daanen, R.P., Shur, Y., Peterson, R.A., Krantz, W.B., Raynolds, M.K., Gould, W.A., Gonzalez, G., 
Nicolsky, D.J., Vonlanthen, C.M., Kade, A.N., Kuss, P., Kelley, A.M., Munger, C.A., Tarnocai, C.T., Matveyeva, N.V., Daniëls, F.J.A., 2008. Arctic patterned-ground ecosystems: A synthesis of field studies and models along a North American Arctic transect. Journal of Geophysical Research G: Biogeosciences 113. doi:10.1029/2007JG000504

Wardle, D.A., Walker, L.R., Bardgett, R.D., 2004a. Ecosystem properties and forest decline in contrasting long-term chronosequences. Science 305, 509-513.

Wardle, D.A., Zackrisson, O., Hörnberg, G., Gallet, C., 1997. The influence of island area on ecosystem properties. Science 277, 1296-1299.

Wardle, D.A., Bardgett, R.D., Klironomos, J.N., Setala, H., van der Putten, W.H., Wall, D.H., 2004b. Ecological linkages between aboveground and belowground biota. Science $304,1629-1633$.

Washburn, A.L., 1980. Geocryology: a survey of periglacial processes and environments. Edward Arnold, London. pp. 406

Welc, M., Bünemann, E.K., Fließbach, A., Frossard, E., Jansa, J., 2012. Soil bacterial and fungal communities along a soil chronosequence assessed by fatty acid profiling. Soil Biology and Biochemistry 49, 184-192.

Wendeberg, A., 2010. Fluorescene in situ hybridization for the identification of environmental microbes. Cold Spring Harbor Protocols 5. doi:10.1101/pdb.prot5366

Wood, S.N., 2004. Stable and efficient multiple smoothing parameter estimation for generalized additive models. Journal of the American Statistical Association 99, 673-686. 


\section{Figure Legends}

Fig. 1 Images of non-sorted circles (NSCs), the research site location and soil sampling design. (a) A NSC. A 1-m measure is placed between the center of the NSC and the edge of the inner domain. (b) Landscape of the research site. Many NSCs are present on the ground, and these features are common in tundra ecosystems in this region. (c) Location of the research site. The filled triangle indicates our research site. (d) Soil sampling design (left panel). Six sampling points were assigned between the center of NSC and the edge of the outer domain. Aboveground vegetation is absent or relatively poor at locations 0,1 , and 2 , while plants are densely colonizing at locations 3,4 , and 5 . A humus layer was present only at locations 3, 4, and 5. This sampling design is identical to that of Makoto and Klaminder (2012). Plant community composition changed dramatically along this transect because of cryoturbation in the system (right panel). The panel is reproduced based on the data in Makoto and Klaminder (2012).

Fig. 2 Abundance of DAPI-positive cells and the relationships between cell abundance and soil properties. (a) Abundance of DAPI-positive cells shown by a box plot. (b) An additive mixed model was fitted to the cell abundance. Humus layer samples were excluded from this analysis because the physicochemical properties and cell abundance of the humus samples were very different from those of the mineral soil samples. The thick solid line indicates the fitted curve, and the dashed lines indicate 95\% confidence intervals. (c), (d) Relationships between cell abundance and soil water and carbon contents. Humus layer samples were excluded from this analysis.

Fig. 3 Composition of the prokaryotic community along the NSC vegetation gradients. Numbers on the $\mathrm{x}$-axis indicate distance from the center of NSC, and " $\mathrm{H}$ " indicates humus 
layer samples. Each bar represents the mean value of the relative abundance of each microbial group. The values of the relative abundance of microbial phyla reported here were corrected by subtracting a false positive rate detected by the NON338 probe $(3.8 \% \pm 0.5$ SEM). Data plots with SEM are presented in Fig. S4.

Fig. 4 Principal component analysis (PCA) of the prokaryotic community composition. (a) Scores of the samples are plotted. For the PCA, the relative abundances of prokaryotic groups were transformed by taking the arcsine of the square root. Numbers indicate the distance from the center of NSC, and " $\mathrm{H}$ " indicates humus layer samples. Bars indicate SEMs. Distance had no effects on PC1 and PC2 $(P>0.05$, linear mixed model). (b) Contributions of microbial groups to the ordination. Actinobacteria, $\gamma$-proteobacteria, and Acidobacteria were positively corresponding, while archaea, Bacteroidetes (referred to as CFB in the right panel), $\alpha$-proteobacteria, and $\beta$-proteobacteria were positively corresponding. 


\section{Tables}

Table 1 Probes and hybridization conditions of the CARD-FISH method.

\begin{tabular}{llll}
\hline Probe Name & Target & Sequence $\left(5^{\prime}-3^{\prime}\right)$ & FA $^{1}$ \\
\hline EUB338 & Eubacteria & EUB338 I: GCT GCC TCC CGT AGG AGT & $35 \%$ \\
& & EUB338 II: GCA GCC ACC CGT AGG TGT & \\
& & EUB338 III: GCT GCC ACC CGT AGG TGT & \\
ARCH915 & Archaea & GTG CTC CCC CGC CAA TTC CT & $5 \%$ \\
ALF968 & $\alpha$-proteobacteria & GGT AAG GTT CTG CGC GTT & $25 \%$ \\
BET42a & B-proteobacteria & GCC TTC CCA CTT CGT TT & $35 \%$ \\
GAM42a & $\gamma$-proteobacteria & GCC TTC CCA CAT CGT TT & $35 \%$ \\
CF319a & CFB ${ }^{2}$ & TGG TCC GTG TCT CAG TAC & $25 \%$ \\
HGC69a & Actinobacteria & TAT AGT TAC CAC CGC CGT & $25 \%$ \\
HoAc1402 & Acidobacteria & CTT TCG TGA TGT GAC GGG & $15 \%$ \\
NON338 & - & ACT CCT ACG GGA GGC AGC & $35 \%$ \\
\hline FA indicate & &
\end{tabular}

${ }^{1}$ FA indicates formamide concentration.

${ }^{2}$ CFB indicates phylum Cytophaga-Flavobacteria-Bacteroidetes.

All hybridizations were conducted overnight at $35^{\circ} \mathrm{C}$. Results of the pilot experiments to determine the optimal hybridization condition are shown in Fig. S1. 

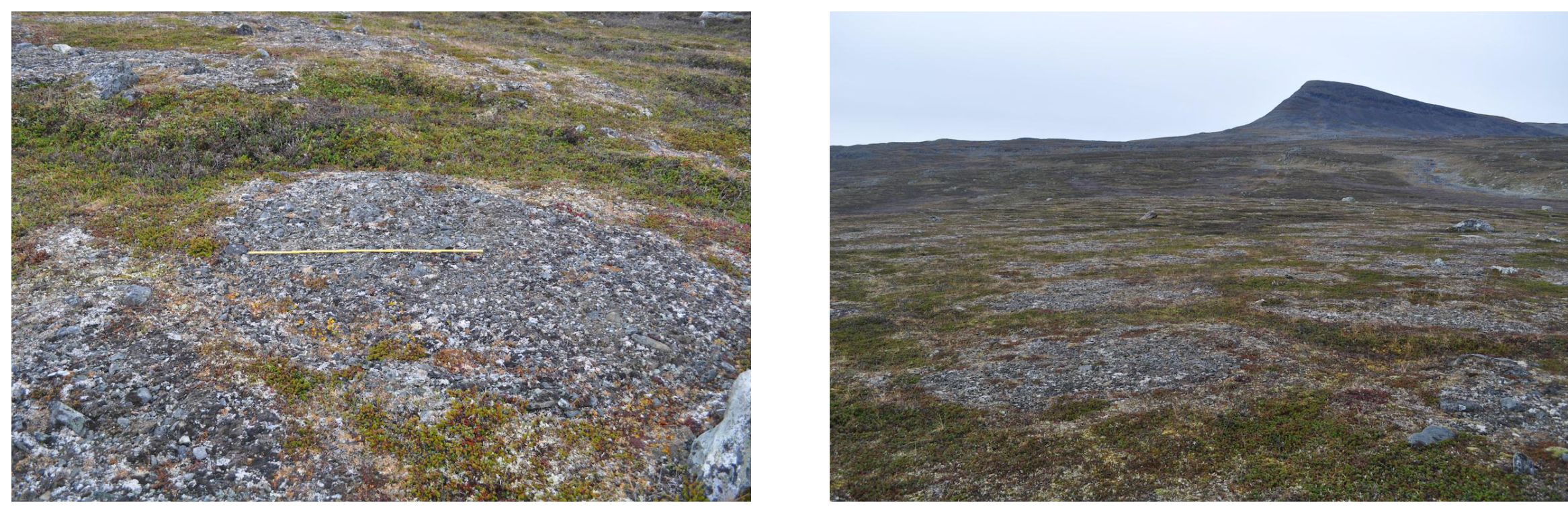

(c)

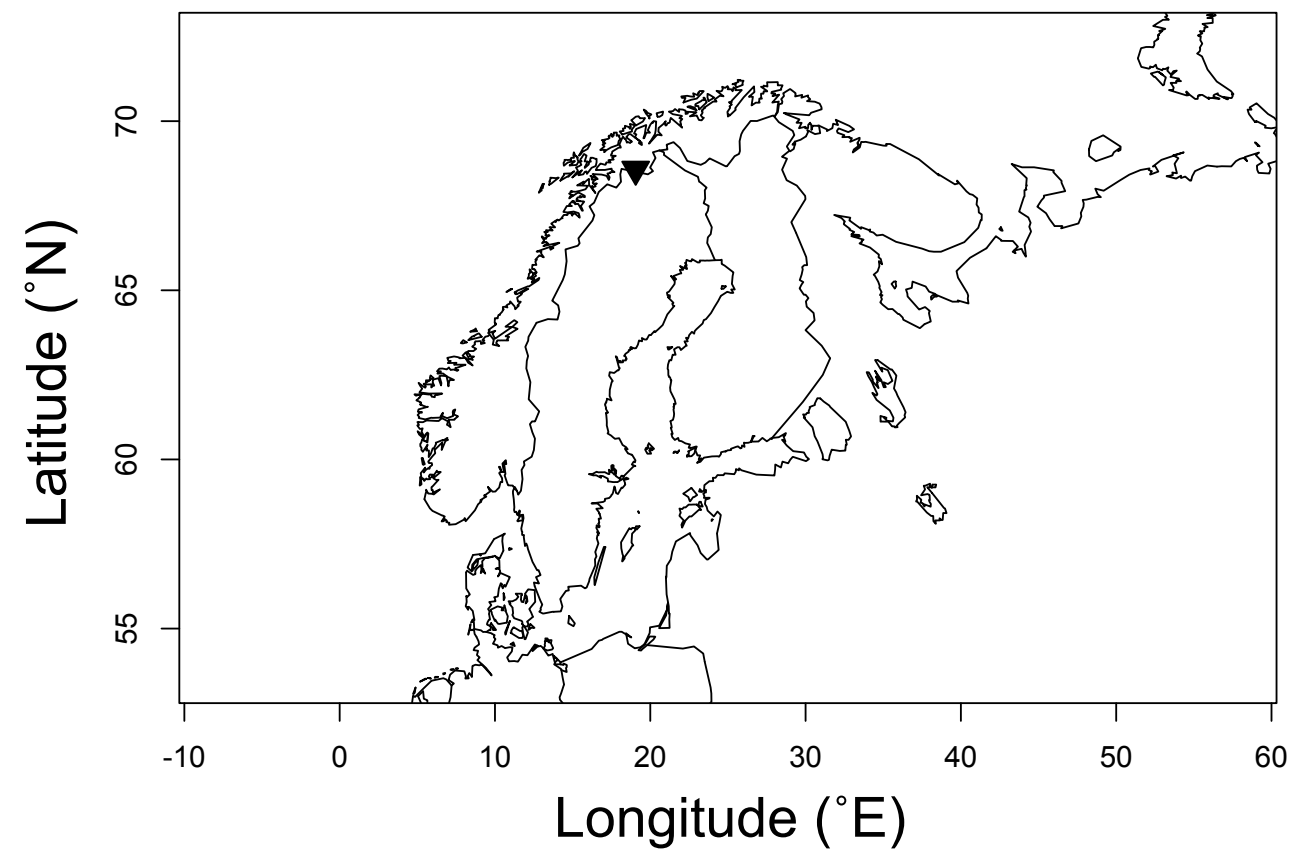

(d)

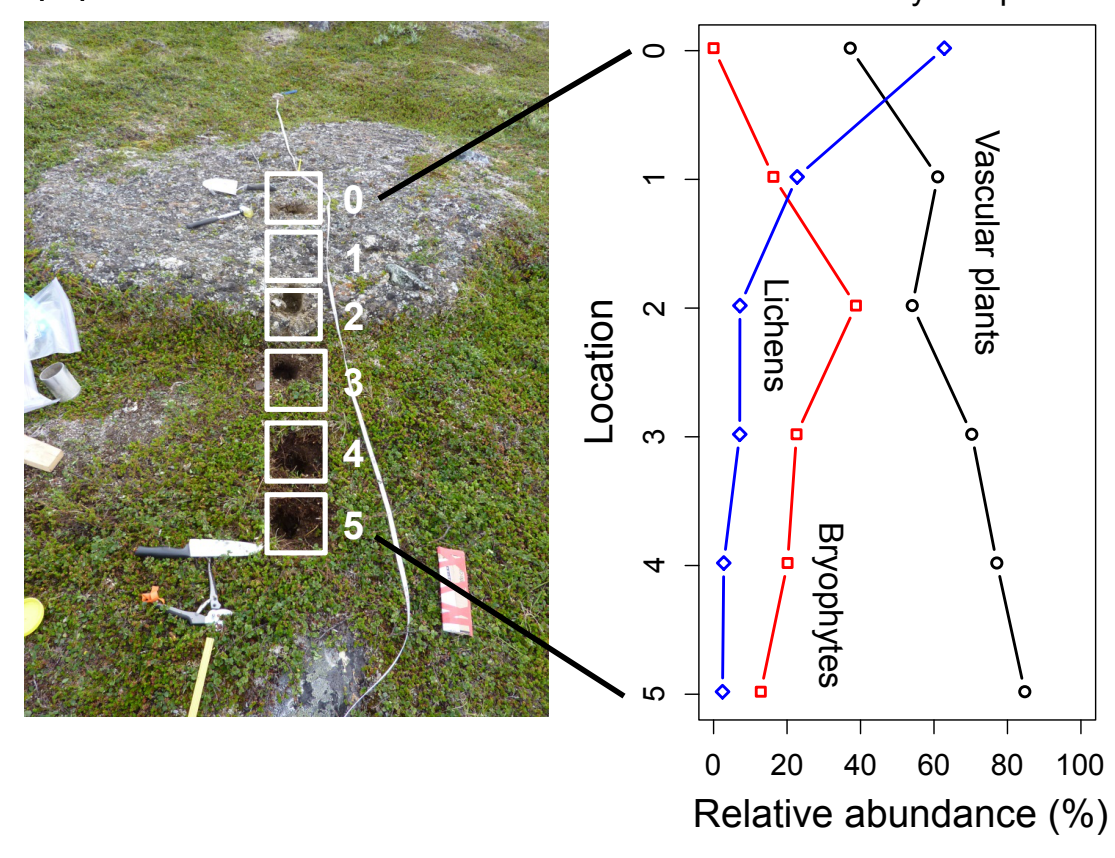

Fig. 1 Ushio et al. 


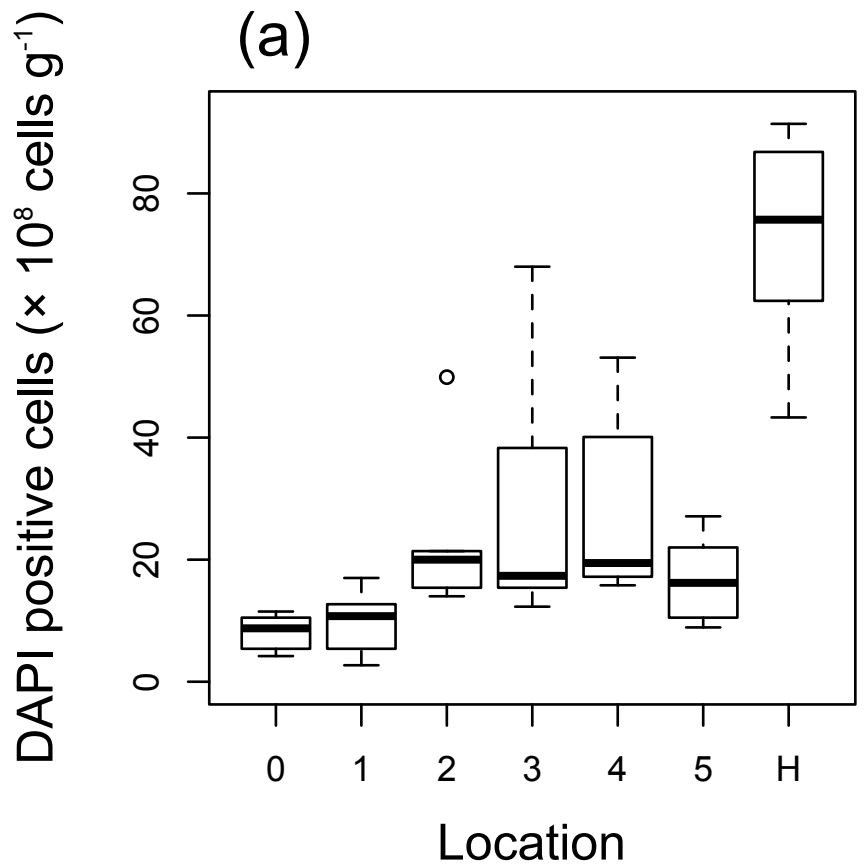

(b)
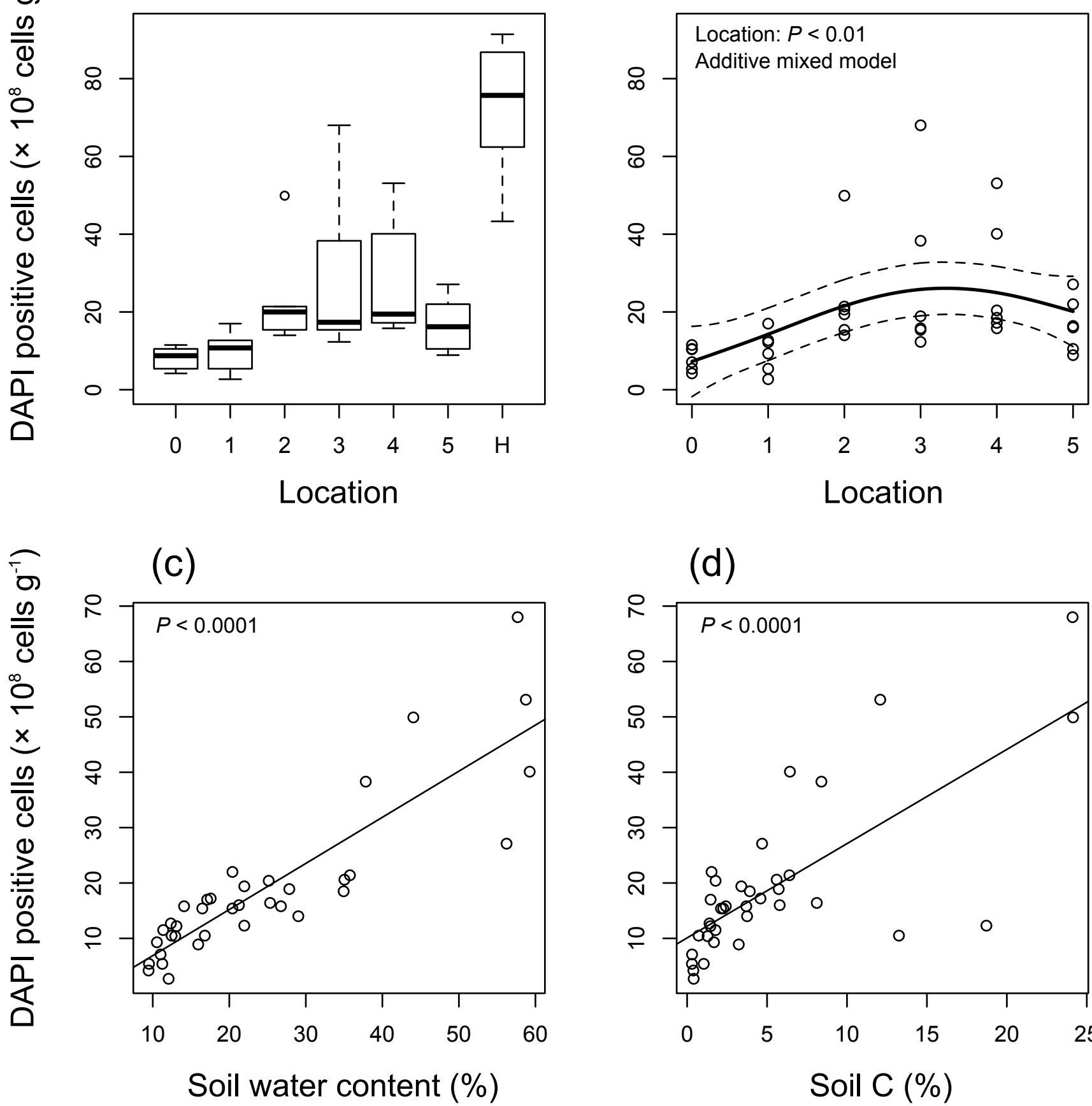

(d)

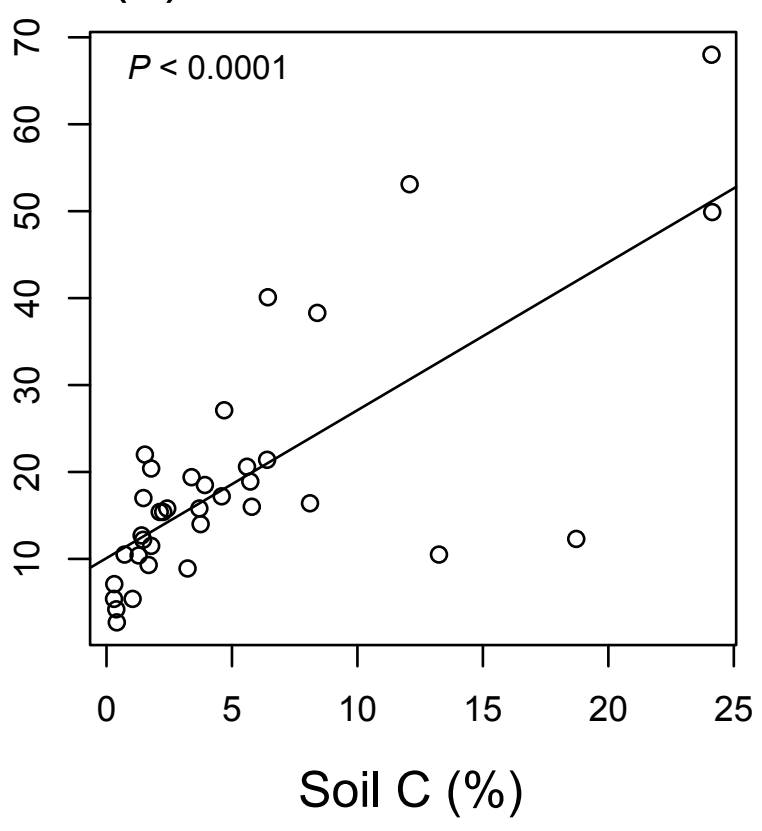

Fig. 2 Ushio et al. 


\section{Prokaryotic community composition}

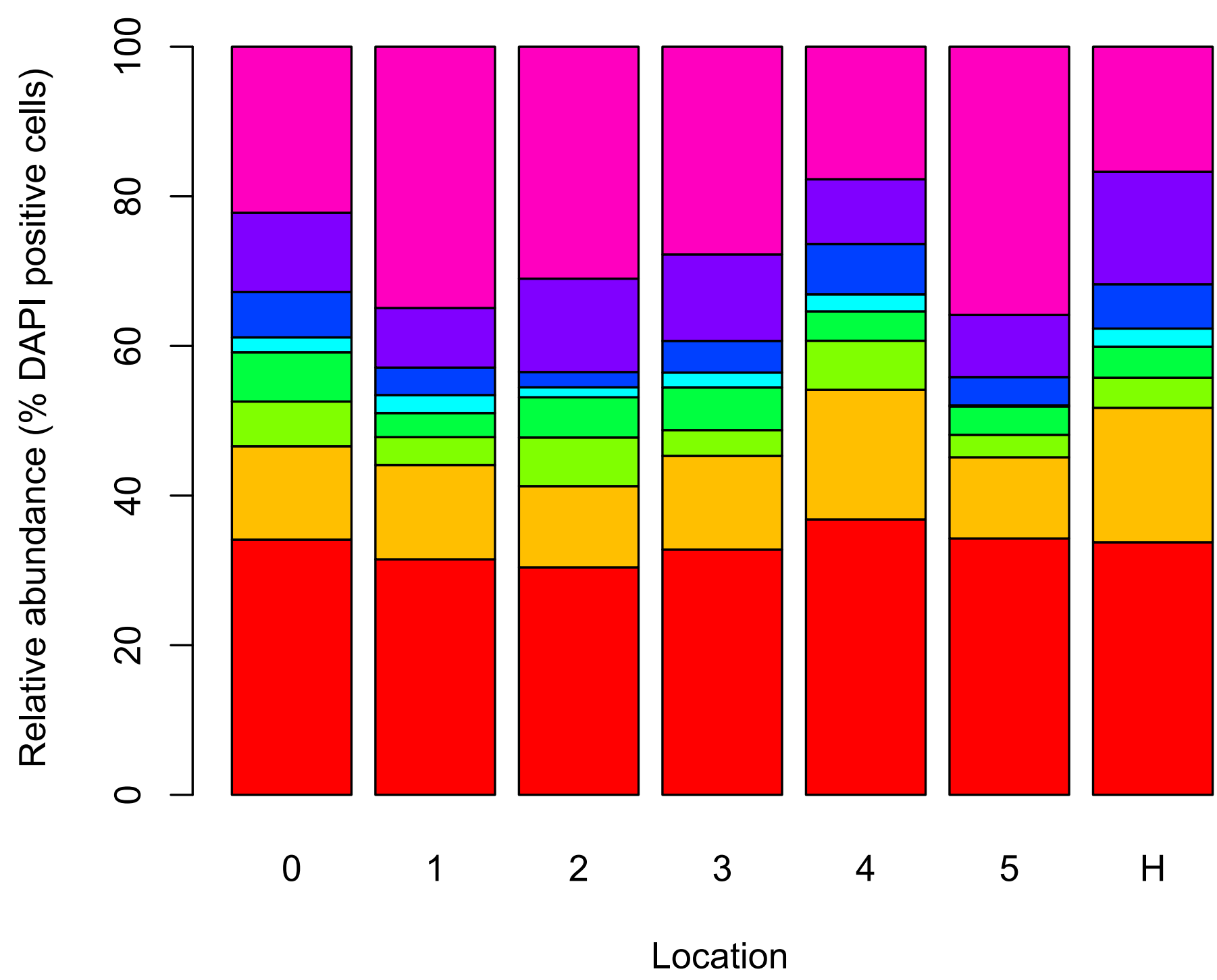

$\square$ Not identified

- HoAc1402 (Acidobacteria)

$\square$ HGC69a (Actinobacteria)

$\square$ CF319a (CFB)

$\square$ GAM42a ( $\gamma$-Proteobacteria)

$\square$ BET42a ( $\beta$-Proteobacteria)

$\square$ ALF968 (a-Proteobacteria)

- ARCH915 (Archaea)

Fig. 3 Ushio et al. 
(a) Samples

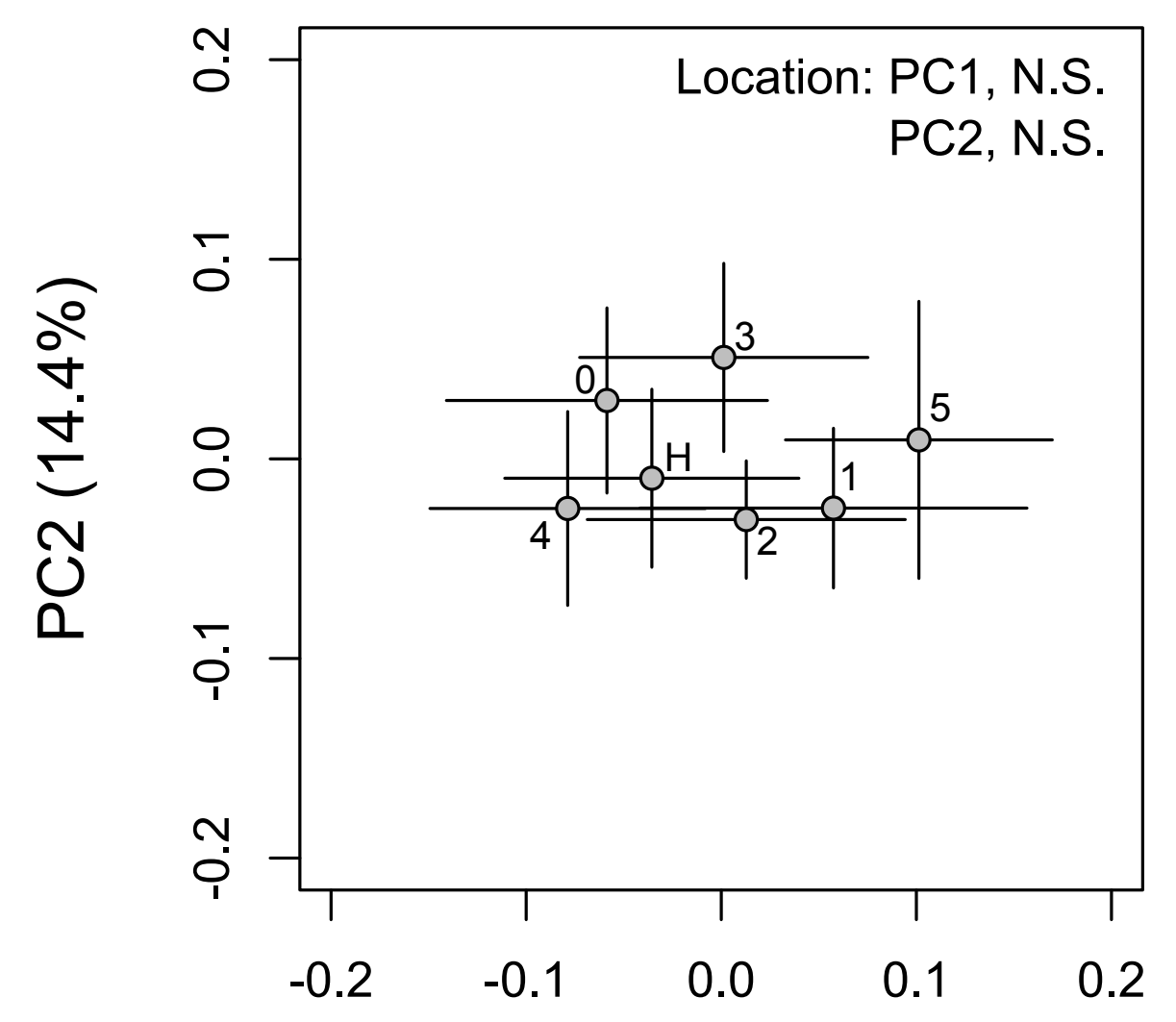

(b) Microbial community

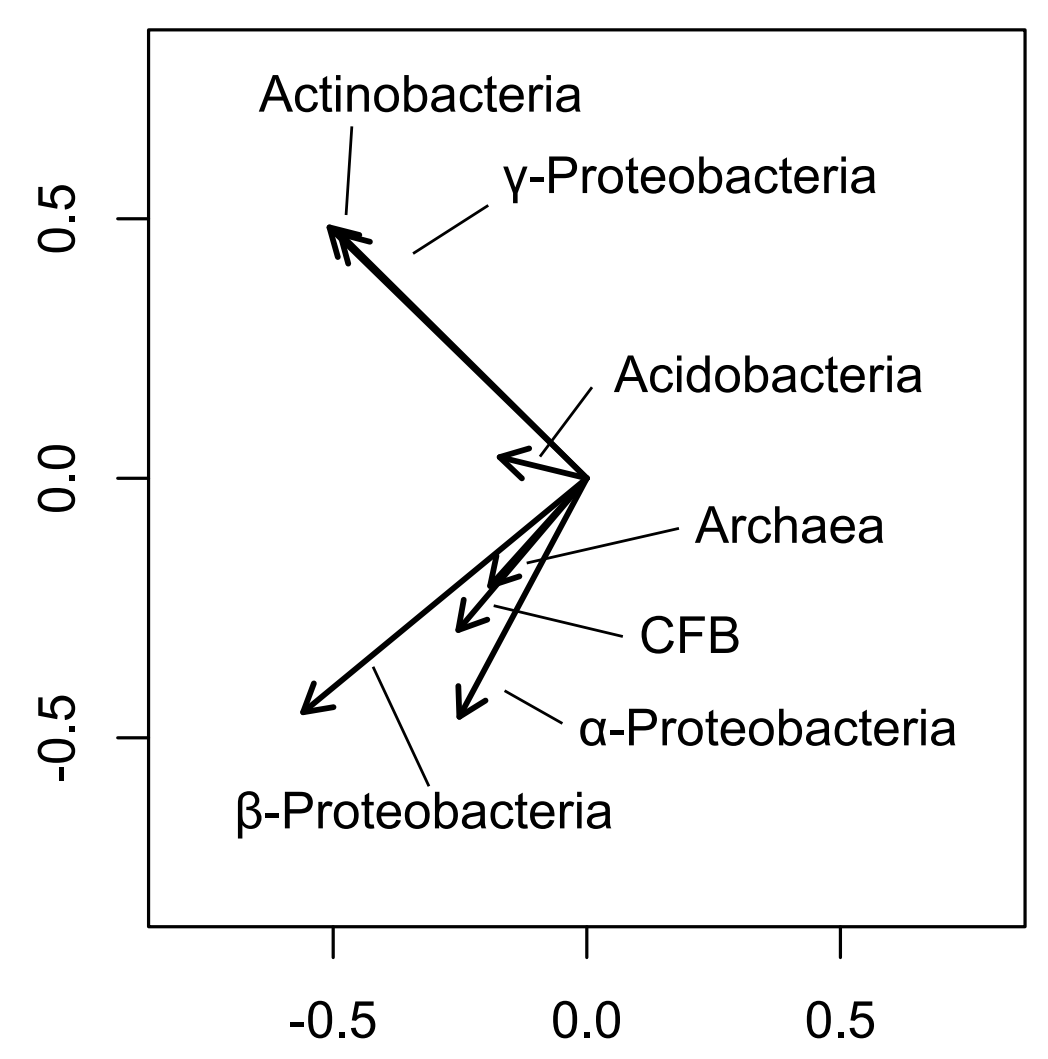

PC1 (41.2\%)

Fig. 4 Ushio et al. 


\section{Supplementary Figure Legends}

Fig. S1 Dependence of CARD-FISH detection percentages on formamide concentration for each probe. Probe names are listed in Table 1. Different formamide concentrations and hybridization temperature were tested for one representative soil sample. Filled black circles and filled red squares indicate detection percentages by hybridizations at $35^{\circ} \mathrm{C}$ and $46^{\circ} \mathrm{C}$, respectively. Black and red solid lines indicate fitted sigmoid curves for the hybridization results at $35^{\circ} \mathrm{C}$ and $46^{\circ} \mathrm{C}$, respectively. Blue triangles and dashed lines indicate formamide concentrations adopted in this study (Table 1). The optimal formamide concentration was determined as the maximal formamide concentration that maintains high values of detection percentages.

Fig. S2 Image examples of soil CARD-FISH. (a) Archaea detected by ARCH915 probes. The bright yellow color indicates cells hybridized with ARCH915 probes. The blue color indicates cells detected by DAPI. (b) Acidobacteria detected by HoAc1402 probes. For (a) and (b), UV (330-350 nm) and blue (460-490 nm) excitation images were merged. Images are taken at 1000 magnification. White bars indicate $10 \mu \mathrm{m}$.

Fig. S3 Sum of the relative abundance of eubacteria (EUB338) and archaea (ARCH915) along the NSC vegetation gradients. Bars indicate SEM. The mean value of all the samples was $93 \% \pm 3.0($ SEM) of DAPI-positive cells.

Fig. S4 Relative abundance of each microbial group along the NSC vegetation gradients. Bars indicate SEM. Distance from the center was not significant for all microbial groups $(P>$ 0.05, linear mixed model). 
(a) EUB338

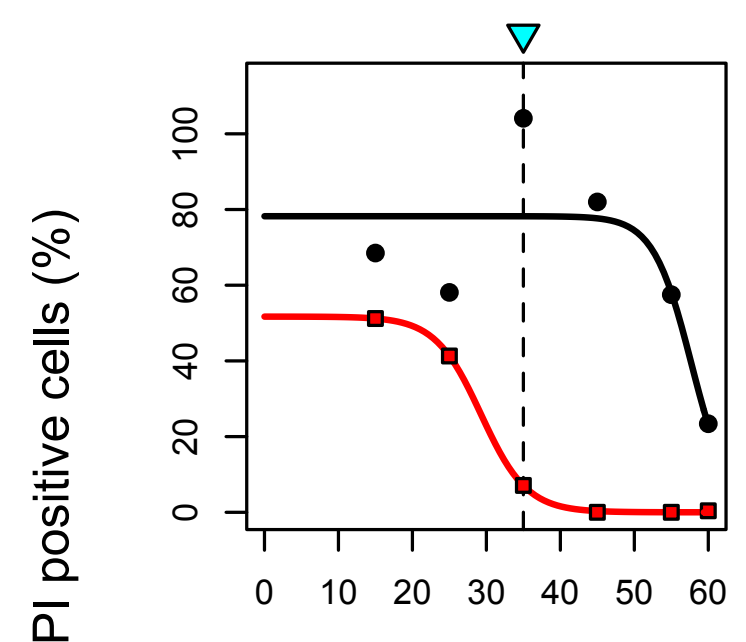

(e) GAM42a

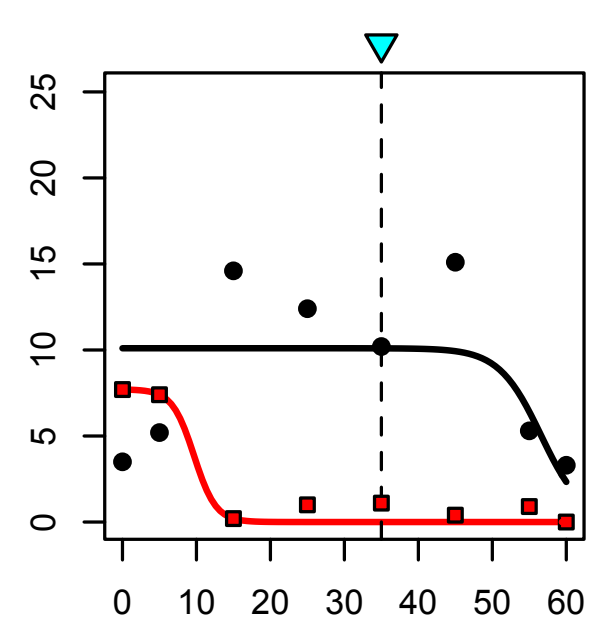

(b) ARCH915

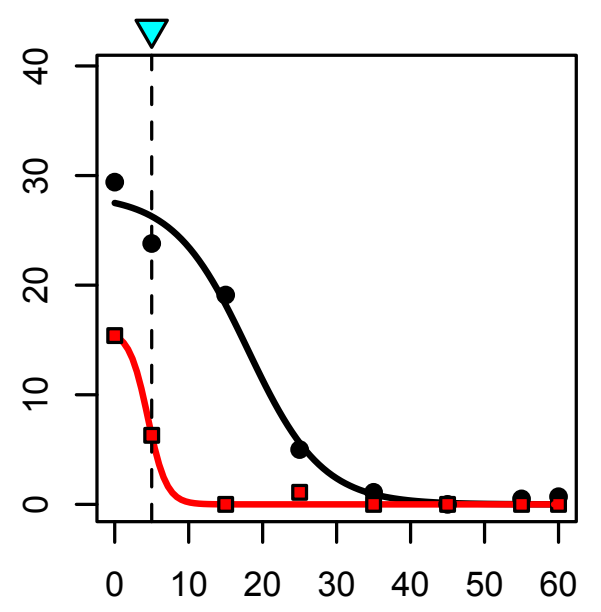

(f) CF319a

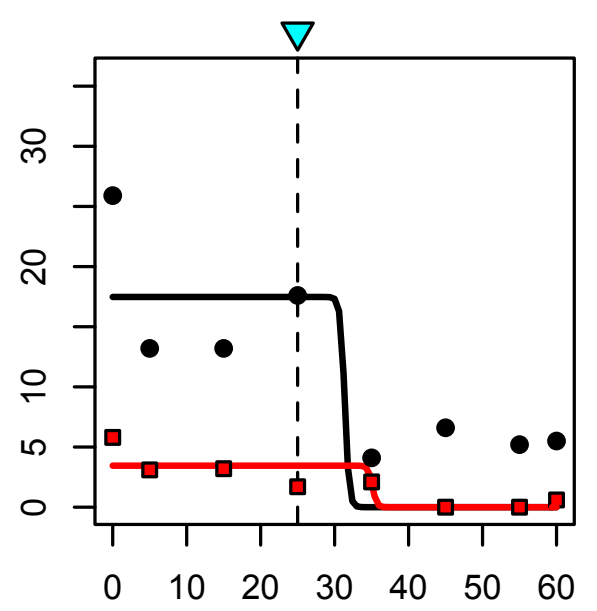

(c) ALF968

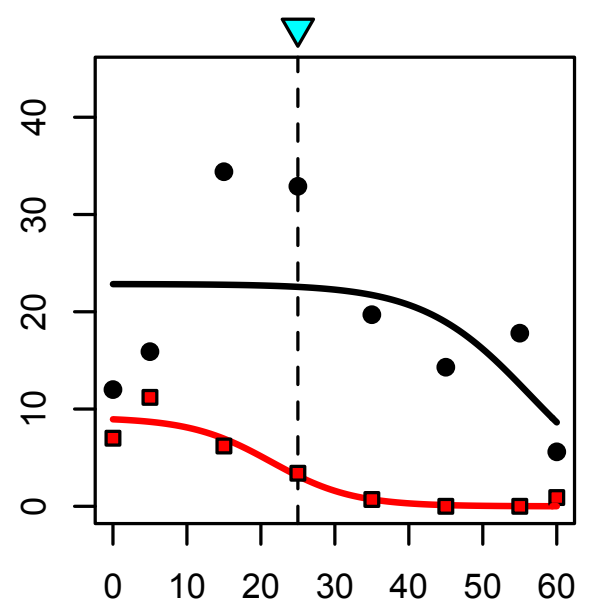

(g) HGC69a

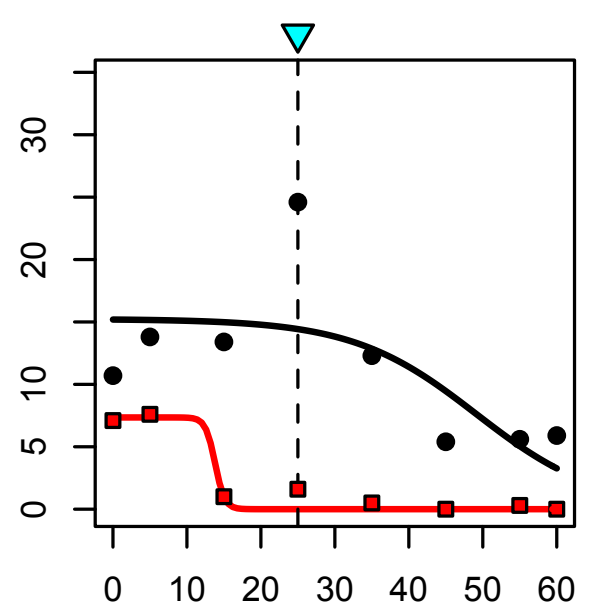

Formamide concentration in hybridization buffer (\%)

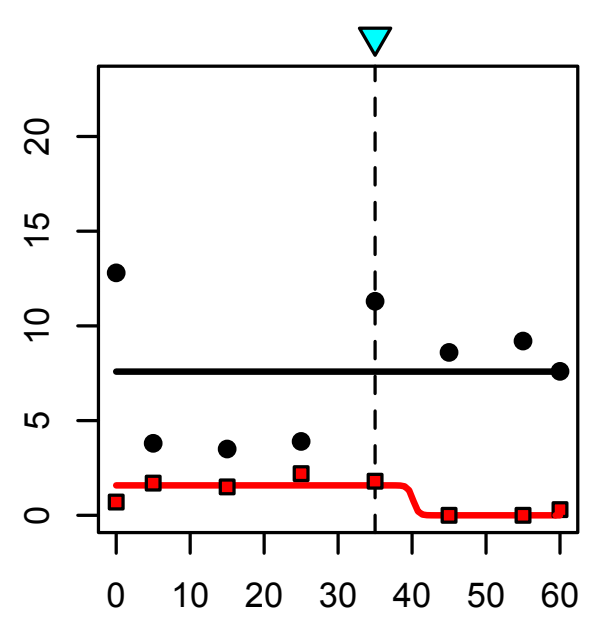

(h) HoAc1402

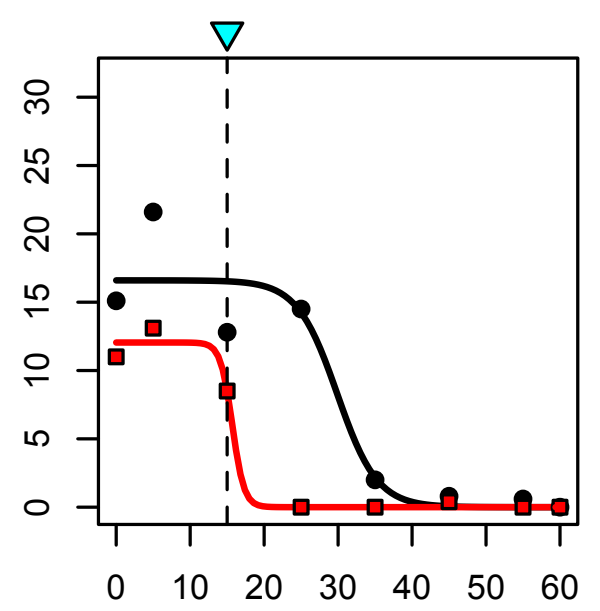

Fig. S1 Ushio et al. 
(a)

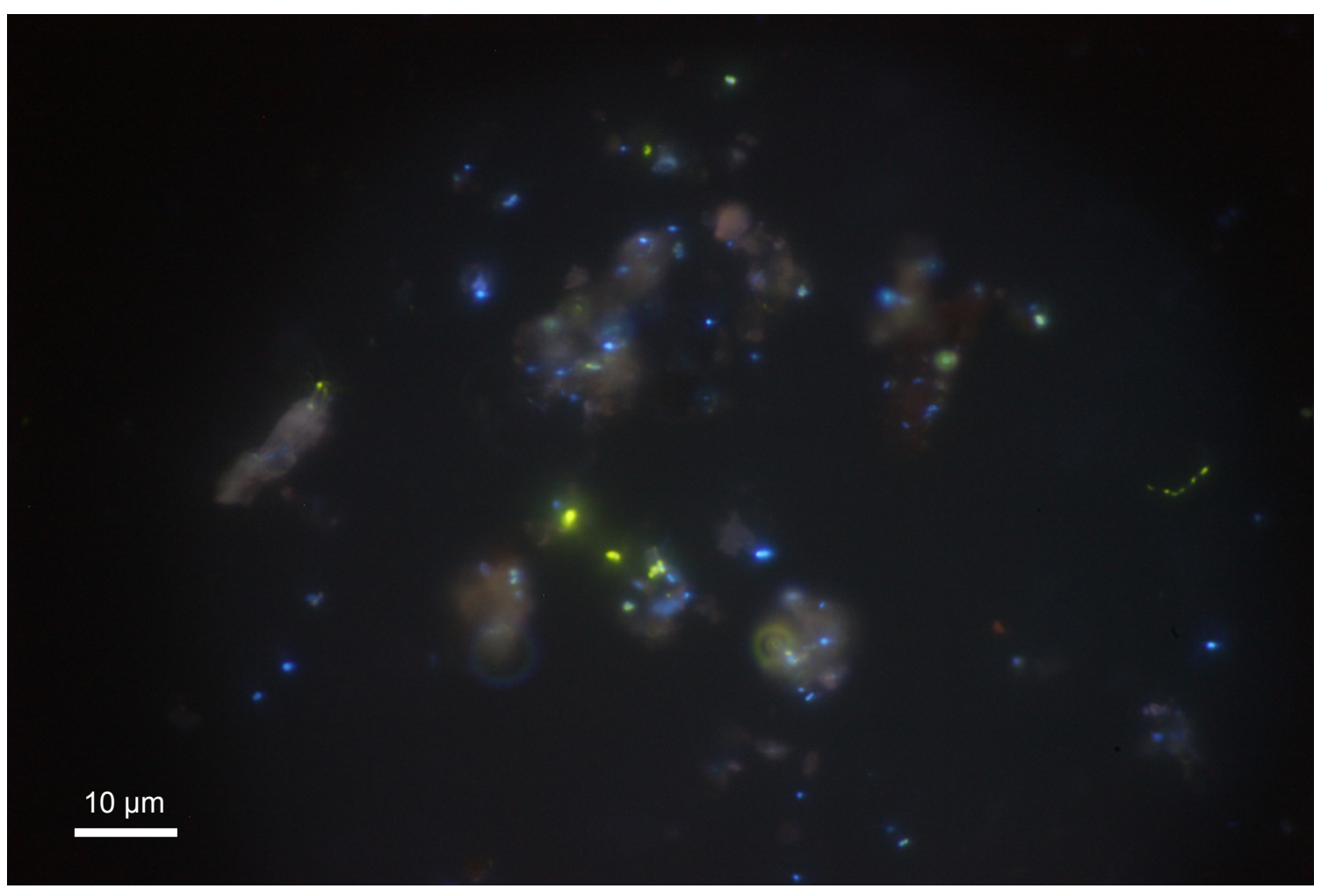

(b)

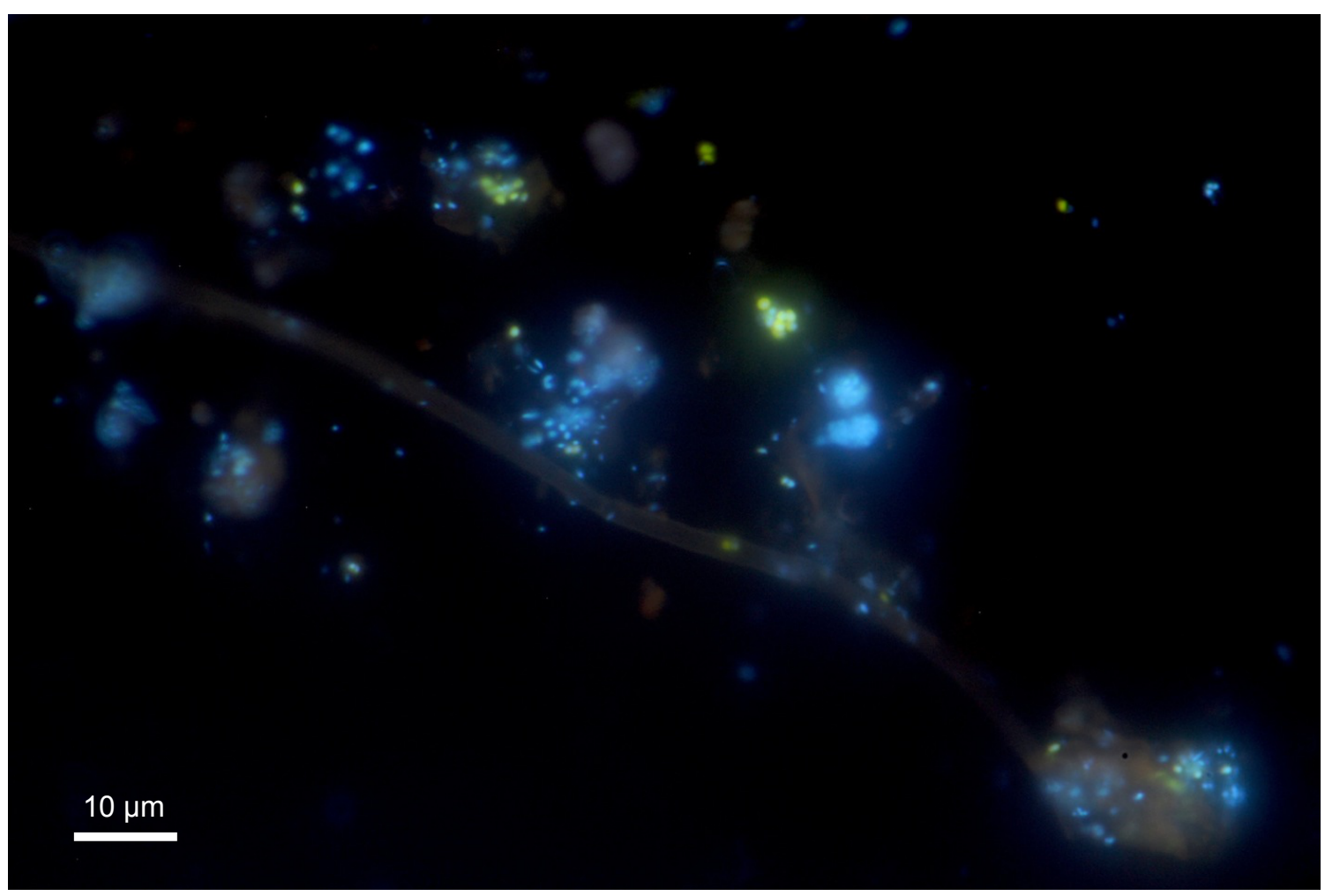

Fig. S2 Ushio et al. 
Eubacteria + Archaea

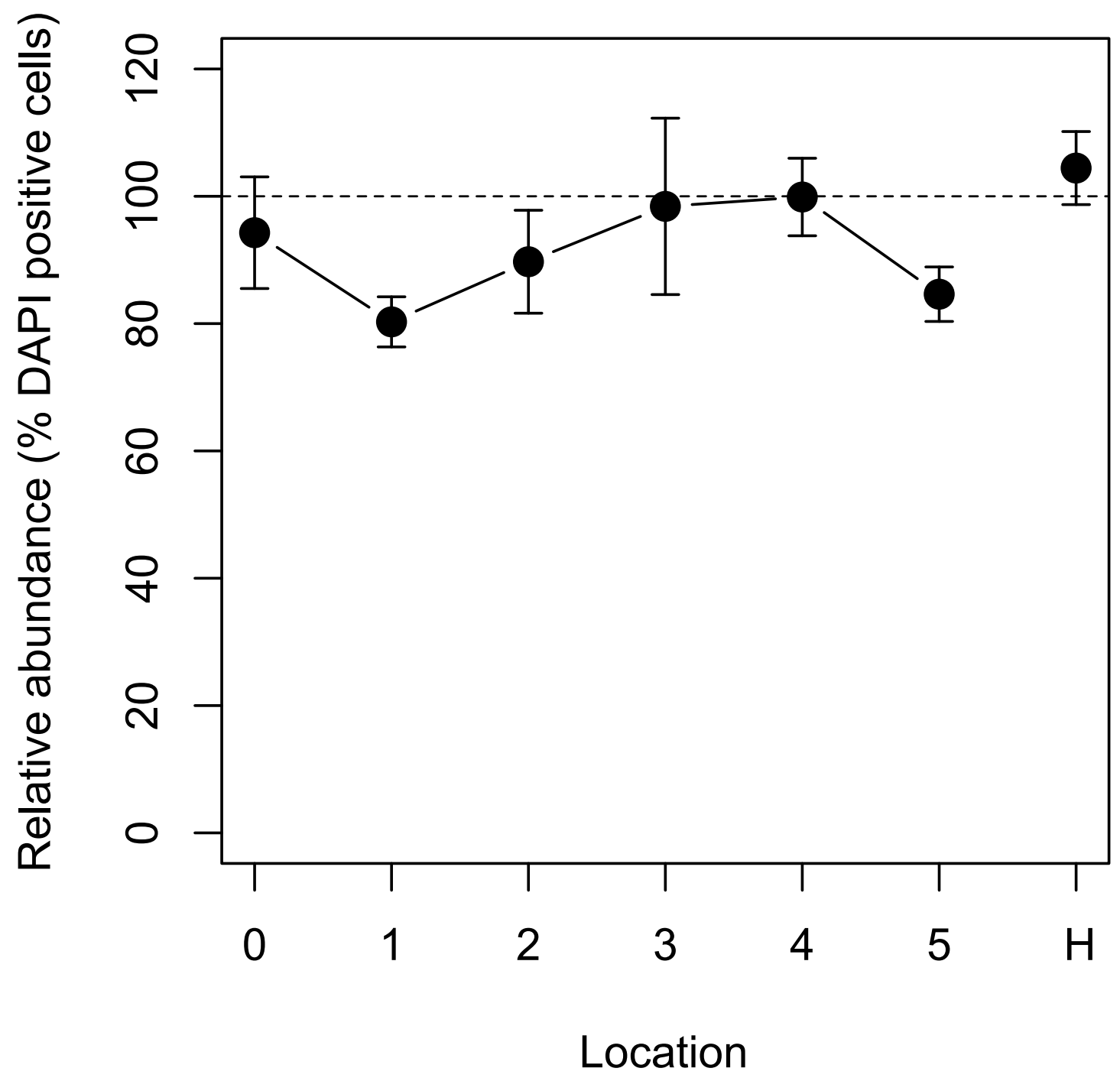

Fig. S3 Ushio et al. 


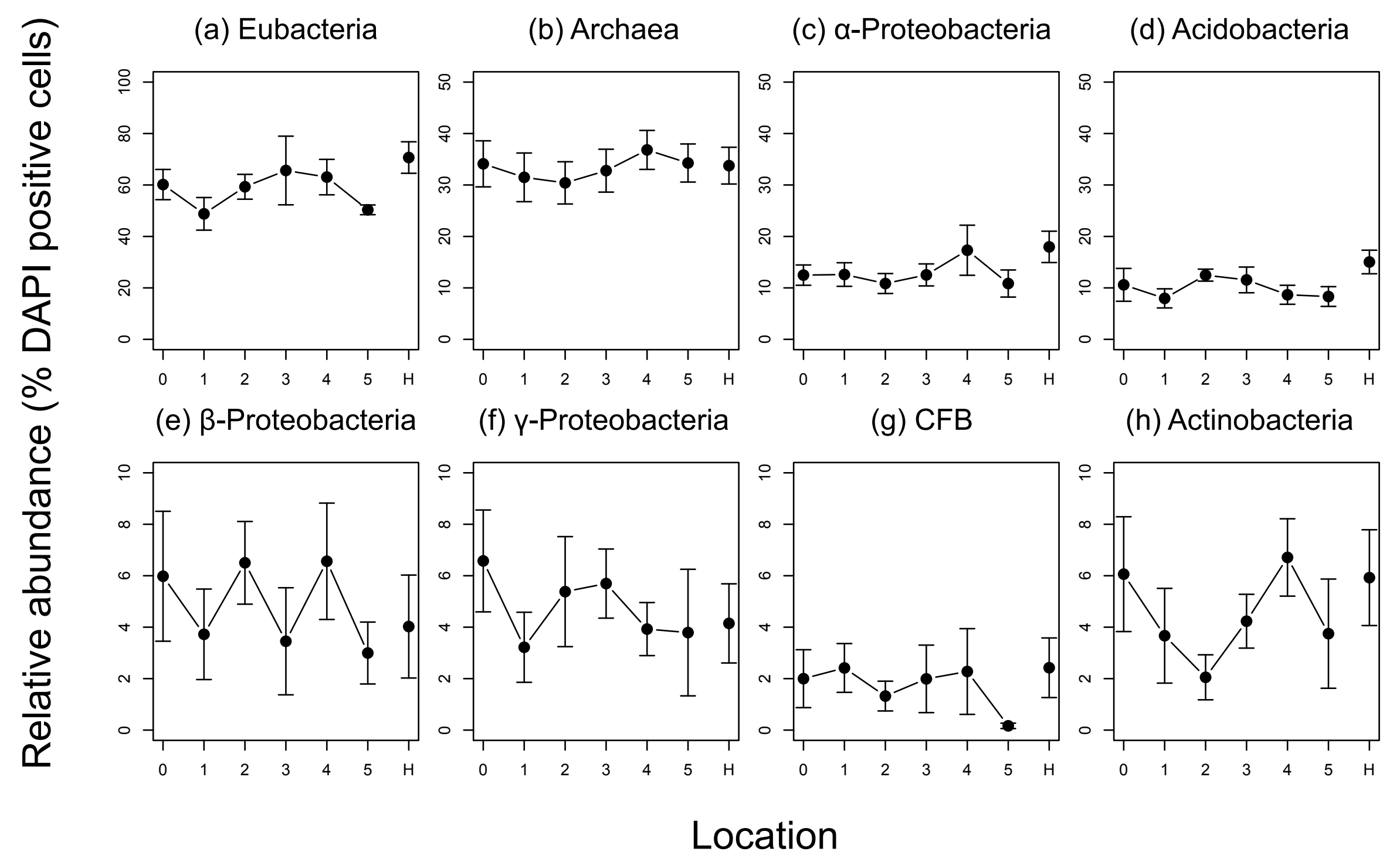

Fig. S4 Ushio et al. 